\title{
The burden and management of patients with IBS: results from a survey in Spanish gastroenterologists
}

\author{
Cristina Almansa ${ }^{1}$, Manuel Díaz-Rubio ${ }^{2}$ and Enrique Rey ${ }^{2}$ \\ ${ }^{l}$ Division of Gastroenterology. Mayo Clinic Jacksonville, Florida, USA. ${ }^{2}$ Department of Gastroenterology. \\ Hospital Clínico San Carlos. Madrid. Spain
}

\begin{abstract}
Background: irritable bowel syndrome (IBS) is a common and complex disorder. Though it is estimated that IBS constitutes an important part of the gastroenterology (GI) practice, the burden of this problem in the GI outpatients' clinics in Spain is unclear.

Aim: the aim of this study is to obtain a "shot" of the burden and management of this syndrome in the daily GI practice.

Methods: 508 general gastroenterologists from all over the country were approached and asked to complete a survey that included questions about their daily practice and the definition, diagnosis and treatment of IBS.

Results: $55 \%$ of the surveyed physicians estimate that IBS constitute between a quarter and a half of all their consultations; and pointed out that most of these patients were referred from primary care. Overall, the Spanish gastroenterologists show an adequate knowledge of the different diagnostic criteria, though they do not always follow the current guidelines. Up to $55 \%$ of the physicians always perform a complementary test to support their diagnosis and $40 \%$ order a diagnostic test only in older patients (> 50 years) or in presence of alarm symptoms. Interestingly, $80 \%$ of the gastroenterologists start empirical treatment based on the patients' symptoms.

Conclusions: though Spanish gastroenterologists seem to have an adequate theoretical knowledge of the disease, they do not systematically follow current guidelines and tend to manage IBS symptoms based on their own criteria.
\end{abstract}

Key words: Irritable bowel syndrome. IBS guidelines. Diagnostic criteria. Clinical management.

Almansa C, Díaz-Rubio M, Rey E. The Burden and Management of Patients with IBS: Results from a Survey in Spanish Gastroenterologists. Rev Esp Enferm Dig 2011; 103: 570-575.

Acknowledgement: This study has been supported by an unrestricted grant from Menarini España.

Received: 26-04-11.

Accepted: 05-05-11.

Correspondence: Enrique Rey. Department of Gastroenterology. Hospital Clínico Universitario San Carlos. c/ Profesor Martin Lagos s/n. 28040 Madrid, Spain.

e-mail: Rey.enrique@med.ucm.es

\section{INTRODUCTION}

Irritable bowel syndrome (IBS) is a common disorder (1). In Spain, it affects up to $10 \%$ of the population (2), and $40 \%$ of them ask for medical attention (3). Though it is estimated that IBS constitutes an important part of the gastroenterology (GI) practice, the burden of this problem in the GI outpatients' clinics in Spain is unclear $(4,5)$.

IBS can be difficult to manage; such complexity is mostly due to the lack of a specific diagnostic marker but also due to the lack of a specific treatment. International (6-9) and national (10) clinical guidelines have been implemented with the aim of helping the clinician in the management of IBS. These guidelines have been developed by consensus of experts based on the current symptom-based diagnostic criteria and the review of the literature. The first symptombased criteria were elaborated by Manning in 1978 (11), and these were later substituted by the Rome symptombased criteria: Rome I in 1994 (12), Rome II in 1999 (13) and most recently Rome III in 2006 (14).

The use of symptom-based diagnostic criteria allows us to perform a positive diagnosis of IBS instead of an exclusion one. However, it has been reported that up to $72 \%$ of physicians from different specialties in the USA (GI, internal medicine and primary care) still consider IBS as a diagnostic of exclusion, which lead to over prescription of diagnostic tests and increases unnecessarily the costs (15). Whether this approach is also followed in Spain, which has a completely different healthcare system than the USA, remains uncertain though a priori seem to be unlikely.

The results of a Delphi survey performed in 2003 among GIs and primary care physicians in Spain showed that Spanish physicians do not agree to identify only one as the best diagnostic strategy in patients with suspected IBS, while they agree to treat IBS patients according to their leading symptoms (16). This survey, though limited by its small sample size, suggests that the practical management of IBS is different in our country than in the USA. 


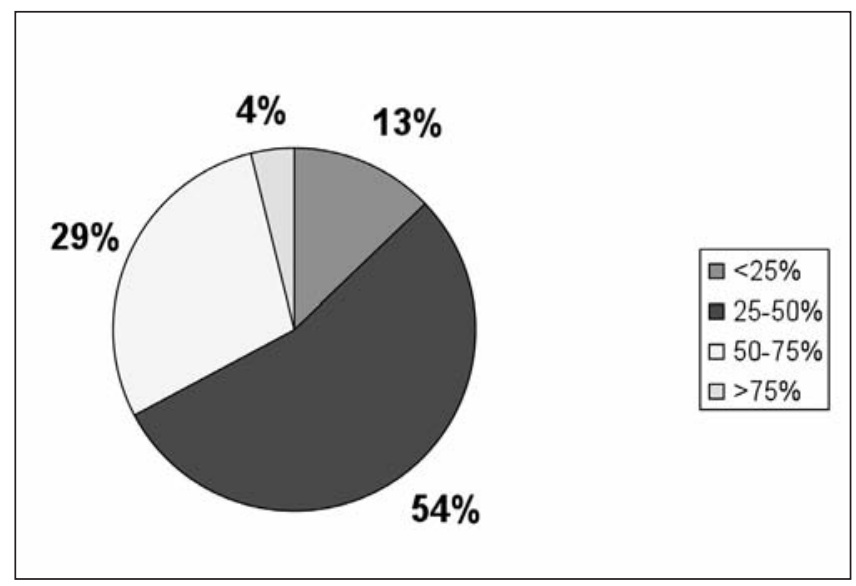

Fig. 1. Rate of patients diagnosed with IBS from the total of patients seen in the Gl outpatient's clinics.

The aim of our study is to obtain a "snapshot" of the burden and daily management of IBS in the GI daily practice in Spain.

\section{METHODS}

\section{Design}

Cross-sectional survey addressed to GI specialists from all over Spain.

\section{Sample}

It is estimated that there are about 2,500 to 3,000 GI specialists working in Spain, though unfortunately it does not exist any formal registry of the specialty that can be easily accessed to confirm this information. Therefore we decided to approach the gastroenterologists in their work place (public and private hospitals and outpatients clinics from all over the country) and asked them to fill our survey, until we reached a size sample of 500. GI fellows and gastroenterologists that spend more than $75 \%$ of their time focused in a specific GI area were excluded.

\section{Questionnaire}

We used a modified version of the 26 item questionnaire that we previously designed for the 2003 Delphi survey (16). In this new version we asked the physicians how often do they perform a specific task (responses ranging from always to never) instead of asking them which was their level of agreement with the performance of such task (responses ranged from totally agree to totally disagree). In addition, we transformed the Delphi's open responses into affirmative or negative statements.

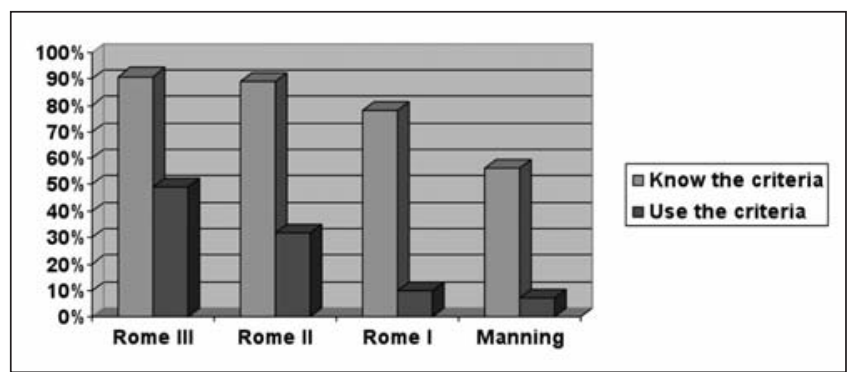

Fig. 2. Proportion of gastroenterologists that know and use the different symptom based diagnostic criteria.

\section{Analysis}

We performed a descriptive analysis of the subjects' responses.

\section{RESULTS}

\section{Participants}

508 GI specialists from all over Spain completed the survey (142 from Andalucía, 71 from the Madrid area, 69 from Cataluña, 58 from the Valencian region, 32 from Galicia, 25 from Castilla-La Mancha, 23 from Castilla León, 23 from the Canary Islands and 21 from the Balearic Islands).

Up to $60 \%$ of the specialists referred to attend more than 50 patients per week while only $9 \%$ of them referred to attend less than 30 . When they were specifically asked about which proportion presented with IBS, 55\% pointed that this rate was between $25-50 \% ; 29 \%$ of them estimated that IBS represented around $50-75 \%$ of their consults, $13 \%$ of them estimated than less than $25 \%$ and only $4 \%$ referred that IBS constituted more than $75 \%$ of their patients' volume (Fig. 1).

\section{Patients' referral source and reasons}

According to $66 \%$ of the physicians surveyed, $70 \%$ or more of the IBS patients were referred from primary care; while only $6 \%$ estimated that less than $25 \%$ of their IBS patients were referred from primary care. When asked about the reasons for referral, the doctors surveyed considered that $50 \%$ were referred for diagnosis, $6 \%$ for treatment prescription and $44 \%$ for both diagnosis and treatment.

\section{IBS clinical classification}

Pain was the predominant symptom in most patients with IBS according to $52 \%$ of the physicians; while $4 \%$ of the gastroenterologist referred that they never attend any patient with abdominal pain. $29 \%$ of the gastroenterologists pointed the alternating or mixed bowel habit as the most frequent, 
Table I. Physicians' evaluation of the different diagnostic tests, classified according the patients' predominant symptoms

\begin{tabular}{|c|c|c|c|c|}
\hline Diagnostic test & Diarrhea & Constipation & Pain & Mixed \\
\hline $\mathrm{CBC}$ and basic serum chemistry & $89 \%$ & $84 \%$ & $86 \%$ & $87 \%$ \\
\hline TSH & $85 \%$ & $68 \%$ & $37 \%$ & $68 \%$ \\
\hline Stool culture & $75 \%$ & $11 \%$ & $15 \%$ & $42 \%$ \\
\hline \multicolumn{5}{|l|}{ Anti-gliadine and } \\
\hline antitransglutaminase antibodies & $81 \%$ & $18 \%$ & $34 \%$ & $53 \%$ \\
\hline Colonoscopy & $66 \%$ & $63 \%$ & $59 \%$ & $70 \%$ \\
\hline Barium enema & $19 \%$ & $38 \%$ & $27 \%$ & $24 \%$ \\
\hline Small bowel radiology & $25 \%$ & $4 \%$ & $17 \%$ & $16 \%$ \\
\hline Abdominal ultrasound & $19 \%$ & $17 \%$ & $60 \%$ & $23 \%$ \\
\hline Upper endoscopy & $6 \%$ & $3 \%$ & $12 \%$ & $4 \%$ \\
\hline Anorectal manometry & $1 \%$ & $7 \%$ & $2 \%$ & $1 \%$ \\
\hline Do not respond & $1 \%$ & $1 \%$ & $1 \%$ & 0 \\
\hline
\end{tabular}

while $23 \%$ considered the diarrhea and $7 \%$ the constipation. $84 \%$ of all the physicians surveyed agreed that only a minority $(<25 \%)$ of the IBS patients could not be classified according their predominant symptoms.

\section{Diagnosis}

When asked about the overall diagnosis approach, 5\% of the responders referred that they followed a symptombased strategy, 55\% always prescribed a diagnostic test in order to rule out structural diseases and finally $40 \%$ prescribed a diagnostic test only in the presence of alarm symptoms or in subjects older than 50 years.

Table I shows the physicians' evaluation of the different diagnostic tests according the patients' predominant symptoms.

\section{Treatment}

$80 \%$ of the physicians initiate empirical treatment, while $18 \%$ always wait until they receive the result of the diagnostic tests; $2 \%$ do not follow any particular rule. Table II summarizes the response of the gastroenterologists with respect to the different therapeutic options by symptoms groups.

\section{Follow up}

$88 \%$ of the gastroenterologists consider that primary care should be responsible for most patients' follow up, while $11 \%$ considered that this should be responsibility of GI. Interestingly $30 \%$ of the respondents chose not to respond this question.

\section{DISCUSSION}

This study shows the opinion of Spanish gastroenterologists regarding the daily management of patients with IBS.

IBS is one of the most prevalent conditions in the GI practice. Indeed, $55 \%$ of the physicians surveyed estimated that IBS constitutes up to $25-50 \%$ of their consultations and an additional one third of physicians estimate this rate as higher than 50\%; which is in agreement with data from other Euro-

Table II. Treatment of choice $\left(1^{\text {st }}\right)$ and best alternative $\left(2^{\text {nd }}\right)$ according the patients' predominant symptom

\begin{tabular}{|c|c|c|c|c|c|c|c|c|}
\hline \multirow{2}{*}{$\begin{array}{l}\text { Treatment } \\
\text { Choice }\end{array}$} & \multicolumn{2}{|c|}{ Diarrhea } & \multicolumn{2}{|c|}{ Constipation } & \multicolumn{2}{|c|}{ Pain } & \multicolumn{2}{|c|}{ Mixed } \\
\hline & $1^{\text {st }}$ & $2^{\text {nd }}$ & $1^{\text {st }}$ & $2^{\text {nd }}$ & $1^{\text {st }}$ & $2^{\text {nd }}$ & $1^{\text {st }}$ & $2^{\text {nd }}$ \\
\hline$\overline{\text { Diet }}$ & $18 \%$ & $1 \%$ & $16 \%$ & $6 \%$ & $4 \%$ & $4 \%$ & $12 \%$ & $5 \%$ \\
\hline Antidiarrheal & $22 \%$ & $36 \%$ & $1 \%$ & $1 \%$ & $1 \%$ & $1 \%$ & $1 \%$ & $3 \%$ \\
\hline Antispasmodics & $48 \%$ & $36 \%$ & $14 \%$ & $25 \%$ & $90 \%$ & $19 \%$ & $40 \%$ & $44 \%$ \\
\hline Dietary Fiber & $33 \%$ & $18 \%$ & $73 \%$ & $22 \%$ & $10 \%$ & $19 \%$ & $53 \%$ & $26 \%$ \\
\hline Laxatives & $1 \%$ & $1 \%$ & $10 \%$ & $56 \%$ & $1 \%$ & $3 \%$ & $1 \%$ & $2 \%$ \\
\hline Anxiolytics & $5 \%$ & $23 \%$ & $1 \%$ & $10 \%$ & $4 \%$ & $46 \%$ & $4 \%$ & $31 \%$ \\
\hline Antidepressants & $1 \%$ & $9 \%$ & $1 \%$ & $5 \%$ & $1 \%$ & $27 \%$ & $1 \%$ & $12 \%$ \\
\hline Do not respond & $1 \%$ & $1 \%$ & $1 \%$ & $1 \%$ & $1 \%$ & $1 \%$ & $1 \%$ & $2 \%$ \\
\hline
\end{tabular}


pean countries $(4,5)$. Quantitatively, this rate means an important number of patients to be seen by the gastroenterologist; mainly if we consider that the GI average patient volume was ranged between 50-100 patients per week.

More than half of the physicians confirmed abdominal pain as the cardinal symptom in IBS. In addition, most gastroenterologists agree that is rare that a patient with IBS cannot be classified according the predominant symptoms. In general, our physicians consider the symptom-based diagnostic criteria as a simple and useful diagnostic tool, mostly in young patients. Most Spanish GI physicians know and use the Rome II and III criteria, while only a minority know and use the Manning criteria. Therefore, it seems as the Spanish gastroenterologist accept the current diagnostic criteria $(7,10,14)$, and tend to apply them in their daily practice; which contrast with what has been reported in other countries $(17,18)$.

A significant proportion of the doctors surveyed applied a diagnostic approach in agreement with the published guidelines; in general they do not over prescribe diagnostic test, but order a complete blood count, basic serum chemistry and, except when the abdominal pain is the main symptom, a TSH determination. In addition, in patients with diarrhea, our physicians order stool cultures, ova and parasites exam. Though currently there is not enough scientific evidence that support this approach, the truth is that clinically is not an unreasonable strategy and previous diagnostic criteria, such as those of Kruis $(19,20)$ used to include some lab parameters for the diagnosis of IBS.

Most gastroenterologists agree to screen for celiac disease (CD) in patients with diarrhea and occasionally in other IBS subtypes. This strategy is in agreement with previous studies that report a higher prevalence of $C D$ in patients with IBS like symptoms, mainly in those presenting with abdominal pain and diarrhea. The risk of CD in IBS seems to be up to 3-4 folds higher than in the normal population (21). In fact the American College of Gastroenterology recommends routine serological screening for CD in patients with diarrhea or mixed symptoms (19); being preferable the use of tissue-transglutaminase antibodies that are the most sensitive and specific (22).

More than a half of the gastroenterologists recommend the performance of colonoscopy in patients with IBS, mainly in patients with mixed symptoms where the proportion reach the $70 \%$. Despite that there is lack of evidence to support the routine performance of colonoscopy in patients younger than 50 years old, except when red flags or alarm symptoms are present (23); this same approach is also common in other countries, like USA (15).

The therapeutic management of this disorder is also complex, given that to date; there is not any drug available that can successfully control all symptoms of IBS. Current guidelines recommend a symptom based therapeutic approach, which seems to agree with the opinion of the Spanish gastroenterologists. Our physicians recommend the use of antispasmodic and anti-diarrheal drugs in case of diarrhea, dietary fiber and laxatives in case of constipa- tion, antispasmodics when pain is the main symptom and antispasmodics and dietary fiber for those with mixed symptoms. Interestingly, when asked about the use of psychotropic drugs, our physicians rather prescribe benzodiazepines than antidepressants, even when the scientific evidence supports the opposite $(24,25)$.

We do not find important differences between the results of this study and the data obtained in our prior survey addressed to primary care doctors and GI. Our prior study was designed using the Delphi methodology which at the end of the day implied the lost of a number of participants. In this study, we used a cross-sectional design which allowed us to get a larger sample size. In our opinion, the similitude found in the outcomes of both studies reinforces the validity of our results (16).

Our study has an obvious limitation which is that these data represent only the view of the respondents and therefore should be interpreted cautiously. However, this survey is also the best source of information on this topic that is currently available in Spain, representing the opinion of up to $20 \%$ of all Spanish gastroenterologists.

In summary, despite their limitations this study shows the high prevalence of IBS in the GI clinics and suggests that the Spanish gastroenterologist have an adequate theoretical knowledge of IBS but experience certain difficulties in the daily management of this disease. The main pitfalls found in the practice of Spanish gastroenterologists are the prescription of unnecessary diagnostic test and treatments not always evidence-based; but otherwise their approach is in consonance with the strategy used by other gastroenterologists in the international community.

\section{REFERENCES}

1. Rey E, Talley NJ. Irritable bowel syndrome: novel views on the epidemiology and potential risk factors. Dig Liver Dis 2009;41:772-80.

2. Mearin F, Badia X, Balboa A, Baro E, Caldwell E, Cucala M, et al. Irritable bowel syndrome prevalence varies enormously depending on the employed diagnostic criteria: comparison of Rome II versus previous criteria in a general population. Scand J Gastroenterol 2001;36:55-1161.

3. Badia X, Mearin F, Balboa A, Baro E, Caldwell E, Cucala M, et al. Burden of illness in irritable bowel syndrome comparing Rome I and Rome II criteria. Pharmacoeconomics 2002;20:749-58.

4. Harvey RF, Salih SY, Read AE. Organic and functional disorders in 2000 gastroenterology outpatients. Lancet 1983;1:632-4.

5. Dapoigny M, Dyard F, Grimaud JC, Guyot P, van GE. Irritable bowel syndrome and healthcare consumption. An observational study in private gastroenterology. Gastroenterol Clin Biol 2003;27:265-71.

6. Drossman DA, Camilleri M, Mayer EA, Whitehead WE. AGA technical review on irritable bowel syndrome. Gastroenterology 2002;123:210831.

7. Spiller R, Aziz Q, Creed F, Emmanuel A, Houghton L, Hungin P, et al. Guidelines on the irritable bowel syndrome: mechanisms and practical management. Gut 2007;56:1770-98.

8. Gwee KA, Bak YT, Ghoshal UC, Gonlachanvit S, Lee OY, Fock KM, et al. Asian consensus on irritable bowel syndrome. J Gastroenterol Hepatol 2010;25:1189-05.

9. Fass R, Longstreth GF, Pimentel M, Fullerton S, Russak SM, Chiou CF, et al. Evidence- and consensus-based practice guidelines for the diagnosis of irritable bowel syndrome. Arch Intern Med 2001;161:2081-8.

10. Grupo de trabajo de la guía de práctica clínica sobre el síndrome del intestino irritable. Manejo del paciente con síndrome del intestino irritable. Barcelona; 2005. 
11. Manning AP, Thompson WG, Heaton KW, Morris AF. Towards positive diagnosis of the irritable bowel. Br Med J 1978;2:653-4.

12. Drossman DA, Richter JE, Talley NJ, Corizziari E, Thompson WG, Whitehead WE. Functional gastrointestinal disorders. Boston: Little; Brown; 1994.

13. Thompson WG, Longstreth GF, Drossman DA, Heaton KW, Irvine EJ, Muller-Lissner SA. Functional bowel disorders and functional abdominal pain. Gut 1999;45 Suppl 2:II43-II47.

14. Longstreth GF, Thompson WG, Chey WD, Houghton LA, Mearin F, Spiller RC. Functional bowel disorders. Gastroenterology 2006; 130:1480-91.

15. Spiegel BM, Farid M, Esrailian E, Talley J, Chang L. Is irritable bowel syndrome a diagnosis of exclusion?: a survey of primary care providers, gastroenterologists, and IBS experts. Am J Gastroenterol 2010; 105:848-58.

16. Almansa C, Rey E, Bolanos E, Palma M, Alvarez SA, Diaz-Rubio M. Spanish physicians point of view on irritable bowel syndrome (IBS). Results of a Delphi survey. Rev Esp Enferm Dig 2007;99:210-7.

17. Vandvik PO, Aabakken L, Farup PG. Diagnosing irritable bowel syndrome: poor agreement between general practitioners and the Rome II criteria. Scand J Gastroenterol 2004:39:448-53.

18. Charapata C, Mertz H. Physician knowledge of Rome symptom criteria for irritable bowel syndrome is poor among non-gastroenterologists. Neurogastroenterol Motil 2006;18:211-6.
19. Brandt LJ, Chey WD, Foxx-Orenstein AE, Schiller LR, Schoenfeld PS, Spiegel BM, et al. An evidence-based position statement on the management of irritable bowel syndrome. Am J Gastroenterol 2009;104 (Supl. 1) 1:S1-35.

20. Kruis W, Thieme C, Weinzierl M, Schussler P, Holl J, Paulus W. A diagnostic score for the irritable bowel syndrome. Its value in the exclusion of organic disease. Gastroenterology 1984;87:1-7.

21. Ford AC, Chey WD, Talley NJ, Malhotra A, Spiegel BM, Moayyedi $P$. Yield of diagnostic tests for celiac disease in individuals with symptoms suggestive of irritable bowel syndrome: systematic review and meta-analysis. Arch Intern Med 2009;169:651-8.

22. Rostom A, Murray JA, Kagnoff MF. American Gastroenterological Association (AGA) Institute technical review on the diagnosis and management of celiac disease. Gastroenterology 2006;131:1981-2002.

23. Chey WD, Nojkov B, Rubenstein JH, Dobhan RR, Greenson JK, Cash BD. The yield of colonoscopy in patients with non-constipated irritable bowel syndrome: results from a prospective, controlled US trial. Am J Gastroenterol 2010;105:859-65.

24. Heading R, Bardhan K, Hollerbach S, Lanas A, Fisher G. Systematic review: the safety and tolerability of pharmacological agents for treatment of irritable bowel syndrome--a European perspective. Aliment Pharmacol Ther 2006;24:207-36.

25. Ford AC, Talley NJ, Schoenfeld PS, Quigley EM, Moayyedi P. Efficacy of antidepressants and psychological therapies in irritable bowel syndrome: systematic review and meta-analysis. Gut 2009;58:367-78. 